\title{
Xavier Villaurrutia, dramaturgo moderno
}

Xavier Villaurrutia, la figura sobresaliente de la vanguardia del $\Lambda$ teatro mexicano, nunca fué un autor popular. Nunca trató de ganar el aplauso fácil del gran público acomodándose a los movimientos en boga. Para ser oído en los teatros comerciales, fué demasiado abstruso y se distinguió por una fina sensibilidad. Fué del ensayo al relato, del relato a la poesía y de la poesía al teatro dejando en todos los géneros huellas firmes de su delicadísima condición espiritual.

El tema inspirador que parece obsesionar su obra es la muerte. En el curso de su vida literaria no podemos menos de notar que su interés se enfocó en la muerte y en el enigma que la rodea. La angustia del hombre ante la nada, no fué sino otra forma del mismo tema. Sin embargo, esta angustia le otorga al poeta una peculiar serenidad. ¿Es tal vez la reconciliación con el destino que dentro de poco iba a ofrecer la solución a los problemas palpitantes y acabar para siempre con las dudas del espíritu atormentado del poeta?

Al concentrar mi interés en el dramaturgo Villaurrutia y en su preocupación por los misterios de la vida y la muerte, poco pude prever que el fruto de mi investigación serviría de homenaje póstumo al mexicano distinguido, fallecido el 25 de diciembre de 1950 en la ciudad de México, donde había nacido el 3 de diciembre de 1903.

El joven Villaurrutia tomó gran interés en los movimientos literarios, y ya en 1924 dedicó al grupo de sus amigos $L a$ poesía de los jóvenes de México. En 1928, en Ulises, publicó la novela Dama de corazones y en 1940, en La Casa de España, Textos y pretextos. 
Conste que en 1933 Aldous Huxley publicó sus Texts and Pretexts: An Anthology with Commentaries, y seria interesante averiguar si el título es mera coincidencia o si expresa una influencia del autor británico en Villaurrutia. ¡Ojalá pudiera contestarnos esta pregunta él mismo!

Ante todo, Xavier Villaurrutia se considera poeta. Hasta sus obras dramáticas justamente podemos llamarlas "teatro poético." A la poesía se dedicó desde 1926, cuando publicó en Cultura treinta y cuatro Reflejos. En 1933 aparecieron sus diez Nocturnos, en la edición "Fábula", y la primera edición de su Nostalgia de la muerte vió la luz en la editorial Sur, de Buenos Aires, en 1938. La edición aumentada con Otros nocturnos, de 1941, contiene también Décima muerte, y así reaparece en la edición de "Mictlan", en 1946.

Para destacar el perfil del dramaturgo con mayor fuerza, vamos a mencionar también sus demás obras: En 1943 apareció en El hijo pródigo un fragmento del libro Cuauhtémoc o El Aguila que cae, bajo el título de El Exodo. Es una seca descripción histórica del tiempo de Hernán Cortés y su viaje a Honduras iniciado el 12 de octubre de 1524. Se llevó el conquistador al jefe mexicano porque de su persona aún se desprendía una fuerza mágica que tenía el poder de encender rebeliones. Era oro vivo el que llevaba en su persona. Cuauhtémoc comprendió la maniobra calculada de Cortés. También comprendió que era su viaje postrero y se entregó a él como a un sacrificio. La historia comprobó la intuición de Cuauhtémoc, también llamado Guatimozin: al regresar Cortés en 1525, faltaba en su compañía el caudillo indígena.

Como editor, Villaurrutia nos dejó el tomo de Sonetos de Sor Juana Inés de la Cruz de 1931. Durante varios años fué redactor de la revista literaria mensual El Hijo Pródigo. Además participó en la publicación de Contemporáneos, con Ermilo Abreu Gómez, Celestino Gorostiza y Samuel Ramos.

Entre 1928-1932 escribió en Ulises y más tarde en Letras de México. Tomó parte en las actividades del grupo "Proa", bajo la dirección de José de Jesús Aceves y en el grupo "Orientación", con Celestino Gorostiza, como director. Gran número de experimentos culturales se hace en esos años. Desdichadamente les faltó coherencia, ayuda oficial y suficiente interés del público, lo que dió por tesultado que ninguno de ellos tuviera mucha duración. 
Como todo poeta, Xavier Villaurrutia en su busca espiritual descubrió a su filósofo: lo encontró en Heidegger y de aquí la característica que para él tiene el hombre moderno: la de morir y asistir a su propia muerte. Villaurrutia admite que vive la muerte auténticamente todos los días y que tiene la posesión de la angustia del misterio. "La muerte es para mí una constante presencia, un vivirla y palparla segundo a segundo", dice en una entrevista en Tierra Nueva, en 1940. Por eso, tal vez, el mundo que ha creado en su obra es un mundo alucinado.

Al hablar de la "Estética de la muerte", dice su amigo Rodolfo Usigli: "Si la actitud estética del poeta es cuidar la muerte individual como una obra de arte, su actitud filosófica es regresar hacia la muerte... En Xavier Villaurrutia el regreso a la muerte es como regreso a una propiedad, la única intransferible, intocable, inalienable propiedad del hombre."

La muerte era compañera constante de su ser. Ahora, después de su prematuro fallecimiento, sólo podemos preguntarnos si la sombra de la muerte habló dentro de su alma desde sus esfuerzos literarios más tempranos, por la intuición del porvenir.

Ya varios críticos literarios se fijaron en el interés de Villaurrutia por la muerte. Su amigo Ermilo Abreu Gómez escribió en Letras de México, en abril, 1944, un artículo sobre Invitación a la Muerte en el que decía: "La muerte es ... una emoción que se adentra en nosotros, que nos gana, que hasta simpatía nos despierta; en Villaurrutia es como una flor... En esta obra la vida y la muerte se funden en un acto que nadie podría desentrañar nunca. Villaurrutia ha guardado con arte en su obra ... el milagro de la muerte y de la vida"...

En otra ocasión ${ }^{1}$ dice Villaurrutia: "El hombre actual, al menos yo, asiste a su propia muerte y a la de los demás. El "memento mori' y el arte de morir son para mí de una angustiosa actualidad." El reflejo de ese teorema ya se ve en la prosa del joven autor, en Dama de corazones, publicada en las ediciones de Ulises, en 1928. Es un conjunto de retratos que forman la base más bien de un sueño que de la realidad. Mme. Girard, sus hijas Aurora y Susana y el primo Julio, de vuelta de Harvard, se dedican a la música y la poesía y a soñar. Uno de los sueños revela lo más profundo del alma del autor: "Ahora me llevan. ¿Adónde? Al cementerio. Ignoran que 
no estoy dentro del ataúd. Sigo el cortejo..." ¿Quién no recordaría a don Félix de Montemar, variación romántica del tema donjuanesco, participando en su propio entierro?

La misma angustia de lo trágico y enigmático en la vida y la muerte, persigue la mente del poeta romántico y del autor moderno. Los sueños forman la base de Dama de los corazones. Para Aurora, todo lo que no es soñado no es vida: “¿Dormir sin soñar? ¿Qué otra cosa es sino morir?" En su modo misterioso de pensar, Aurora es la hermana espiritual de María Luisa, protagonista de la pieza. ${ }_{E}$ En qué piensas?, donde el tiempo real alterna con el tiempo psíquico, en turnos irrevocables.

¿En qué piensas? es un misterio en un acto y es uno de los cinco "Autos profanos". Xavier Villaurrutia no olvida nunca que la condensación — del idioma, de las situaciones, de las ideas- es siempre mejor que la dispersión" 2 y por eso, tal vez, prefiere escribir poesías breves y piezas en un acto como los "Autos profanos." Los llama ejercicios y dice de ellos que son al drama lo que el soneto es a la poesía: resonancia e imágenes.

Se estrenó En qué piensas? en el teatro Hidalgo, en 1934. Como es un episodio de la vida emocional de jóvenes menores de treinta años, tenía el autor, al escribirlo, la misma edad que sus personajes. La heroína, María Luisa, piensa en el amor o en nada. De sus tres amantes, Carlos la amó, Víctor la ama y Ramón la amará, mientras el desconocido no supo esperar. María Luisa los ama a todos en el tiempo, no a un tiempo. A cada uno le asegura: "Pienso en ti." Sin embargo, al encontrarse con los tres a la vez, confiesa que no piensa en nada. Su amor está dividido en varias partes "del tiempo", otorgándole a su espíritu una complejidad rara.

Otro enigma en un acto, dedicado a Celestino Gorostiza, se titula Parece mentira. Así como ¿En qué piensas? fué dirigido por $\mathrm{Ce}-$ lestino Gorostiza en 1934, (en el Teatro de Orientación). Por medio de una carta anónima, se cita al marido en la sala de espera del abogado, para comprobar la infidelidad de su mujer. Aparecen tres mujeres, casi iguales, cada una con la cara cubierta por un velo, y salen una tras otra, sin que el marido haya podido averiguar, si entre ellas, estaba la mujer infiel, ni poder explicar la situación al abogado. Se califica el acto de "enigma", y lo es de veras. En la pieza el autor nos presenta nada menos que las dudas y la incertidumbre 
que llenan la mente humana, sin ofrecer solución alguna al misterio. Al bajar el telón participamos de las dudas, que envuelven la vida del héroe como la nuestra. Los tres momentos diferentes del tiempo de Parece mentira y de ¿En qué piensas? se reúnen en el tiempo psíquico y dan a los dos enigmas dramáticos un carácter indudablemente expresionista. Al mismo tiempo, revelan un desdoblamiento de los personajes tan característico en la obra de Xavier Villaurrutia.

Ha llegado el momento es otro "Auto profano", llamado en el subtítulo "epílogo en un acto", porque se trata de la despedida de dos parejas. Antonio y Fernanda proyectan un viaje a la eternidad porque han perdido su amor y su interés en la vida. No obstante, al llegar el momento de la decisión, son demasiado débiles para realizar su plan. Antes, Fernanda amó a Luis y Antonio amó a Mercedes. En el último esfuerzo por despertar nuevas emociones, vuelven a reunirse; pero el fondo emocional ya está agotado, el amor no reaparece, y la vida cotidiana sigue tranquila... ¿ Por qué cambiaron de papel en el juego de amor? ¿Por qué, al fracasar su amor, les faltó fuerza para acabar con la vida? Los motivos son misteriosos e inexplicables. La debilidad y la falta de decisión predominan en los caracteres, que guiados, por la nostalgia de la muerte, son atraídos al suicidio.

El ausente, es un mito en un acto que nada ha perdido de su característica vanguardista después de veinte años, como pudimos comprobarlo al verlo representar con éxito en ocasión del homenaje póstumo al autor, a principios de enero de 1952, en el Palacio de Bellas Artes, de México. La acción de este "mito" se desarrolla en la ciudad de México. Como tantas veces anteriores, Pedro se ha ido a pasar unos días con su amante. Vuelve, y poco después viene también la mujer, a tomar su puesto al lado de Fernanda, la esposa legítima. Fernanda la rechaza, y entonces ella se va, seguida por Pedro. La esposa sabe que esta vez se despiden para siempre. Tan convencida está de ello, como antes lo estaba de que Pedro iba a volver. Abandonada para siempre, Fernanda, triste, no recuerda más que la bondad del ausente. La ausencia lo idealiza. Es una arquitectura de palabras, de diálogos equilibrados e indispensables; las unidades trágicas rechazan lo accidental y lo pintoresco. Es una 
tragedia mexicana, con su fuerza de fatalidad y su claridad del final trágico.

La pena se acepta con un estoicismo notable, con una reconciliación que casi llega a la alegría. Fernanda es tan fatalista en su predisposición, que le basta con la poca persuasión de la vecina, para hallar consuelo. Acepta su destino, como antes aceptó su desdichado matrimonio. Su actitud es la esencia de lo trágico. La pieza es una tragedia del sufrimiento pasivo, de la reconciliación, con todo lo que el destino prepare. En ella "Villaurrutia posee el mayor dominio del arte de manejar la frase..., su obra es modelo de precisión literaria. Cada vez es más dueño de su arte y de su técnica...,", ${ }^{3}$ como dijo de él Abreu Gómez. Sería difícil explicar cómo la farsa sarcástica Sea usted breve llegó a formar parte del grupo de "autos", que, a pesar de ser llamados "profanos" están llenos de nostálgica melancolía.

En El solterón, otra pieza de un acto, el desaparecido Carlos Ruiz no deja de recordarnos al rico solterón de Schnitzler, 1lamado Anatol. A la hora de morir, Carlos Ruiz llama a sus tres amigos y les revela, en una carta, que ha sido amante de sus esposas. Pero el notario, que acude más tarde, explica la broma y los convence. E1 rico solterón de Schnitzler acabó su vida de placeres egoístas e irresponsables. Encarnado en Carlos Ruiz, se burla de sus amigos hasta después de muerto. Nueve años antes escribió la carta mencionada, y las tres víctimas de su broma heredan su fortuna y callan todo a sus esposas. Como en las piezas anteriores, sobre todo en Parece mentira, nos encontramos con la incertidumbre acompañada de ironía, y con la idea imprescindible de la muerte. Es una obsesión que reaparece aunque envuelta en una capa de comedia satírica.

El yerro candente es una tragedia moderna, de una familia actual, de personajes cotidianos. El lenguaje de los tres actos penetra los sentidos y el discurrir de los personajes está encaminado a la construcción del drama. Las palabras cobran en el autor una intención definida para que sus personajes se aferren a ellas como a un "clavo ardiendo". Aunque el personaje principial, Román, parece un cínico desvergonzado, todos los caracteres son claros y perfectos. Allí no existe el peligro de que el teatro de Xavier Villaurrutia pueda aparecer "tópico", mexicano, puesto que el conflicto entre el amor filial y la conciencia de su destrucción, acerca su personaje femenino 
al de Electra. Sin embargo, se advierte la suficiente comunicación con el ambiente y la naturaleza mexicanos, en la justa proporción que corresponde a las necesidades del teatro mexicano.

La "mexicanidad" de Xavier Villaurrutia, ya la notó Braulio Sánchez Sáez, al escribir en Planalto de Sao Paulo, en 1941: "Em Xavier Villaurrutia tambem achamos o Mexico. Na profundidade, na ansiedade de nos dar um panorama escondido e misterioso do seu ser, com todas as partículas do seus sonhos, transformados na mais rica e delicada poesia." Característicamente intitula su ensayo: "Xavier Villaurrutia, côr e profundidade mexicanas."

Veinticinco años antes de principiar la acción de Yerro candente, Román había seducido a su prima Isabel, que después se casó con Eduardo. El matrimonio se efectuó con el consenso de los tres. Nació Mariana y más tarde otra niña. A los veinticuatro años de edad, Mariana debe escoger entre el padre verdadero y el padre legítimo. Se decide por Eduardo, que la mimó y educó, comprobando la divisa de su padre carnal: "No renuncies a lo que amas, no consientas en que te arrebaten lo que es tuyo, lo que debe ser tuyo." La decisión de Mariana privó a Román de su hija carnal y de la vida de familia. Renuncia a su hija para siempre, y su pena se ve aumentada por remordimientos que traen una nostalgia dolorosa. Paga, por la libertad que prefirió en la juventud. Los diálogos de la pieza están escritos con precisión y técnica puras, y contienen pasión y dialéctica raras.

La hiedra se publicó en 1941, en "Nueva Cultura". Los tres actos explotan modernamente un asunto clásico. Tratan de un conflicto psicológico en ambiente social, en el México de hoy. Al morir su pađre, el joven Hipólito vuelve de España, después de diez años de ausencia. El odio que de niño tenía por su madrastra Teresa se cambia en amor, y Teresa e Hipólito se deciden a partir juntos. Interviene Alicia, prima y novia de Hipólito anunciando que espera un hijo de él. El viaje proyectado fracasa, y Teresa vuelve a quedar sola, mientras Hipólito, para evitar el escéndalo, se casará con su prima.

En La mujer legítima, obra estrenada dos años más tarde en el teatro Ideal, el viudo Rafael lleva a su casa una mujer joven, que también odia su hija, Marta, como a Teresa la odiaba Hipólito. Sin embargo, el odio de Marta tiene causas profundas y psicopáticas, 
pues de su madre heredó la locura. Marta acude a mentiras y falsas acusaciones, para deshacerse de su madrastra Sara. Después de un breve intervalo de felicidad, Sara se va de la casa donde fué insultada por la intrigante Marta. En ambas piezas hay un conflicto entre dos generaciones, causado por una rebelión contra las leyes convencionales. Marta odia a su madrastra Sara porque ésta fué amante de su padre en vida de su madre loca. Los demás hijos la aceptan sin vacilación como mujer legítima de Rafael.

Hipólito se rebeló contra su madrastra cuando era niño. Su amor hacia ella en la edad madura, no es tolerado por los celos de Alicia. El autor goza con "épater le bourgeois": Alicia antuncia que Hipólito es padre del hijo que va a nacer, y no hay escándalo ni suicidio. Solamente seguirá un casamiento, aunque en él falta amor.

En Invitación a la muerte preocupa al autor, además de las leyes de la sociedad convencional, un mal hereditario, como en La mujer legítima, y un problema más bien metafísico, que siempre reaparece en la obra de Xavier Villaurrutia: la preocupación de la muerte. El joven Alberto vive con su madre, la esposa abandonada desde hace años. ¿ Por qué la dejó su marido? Nunca lo sabremos, ni sabremos por qué no admite a su hijo adulto que tiene una amante. El misterio rodea a la familia y preside las relaciones mutuas.

Lo metafísico del drama aumenta por la profesión de Alberto: es empleado de una agencia de inhumaciones. Un atardecer, cuando Alberto está solo en la oficina, viene un cliente para escoger una caja de calidad y de gran solidez. ¿Qué intuición revela a Alberto que el desconocido era su padre? Guardaba una rara simpatía al padre desconocido. Al momento de aparecer como cliente, Alberto intentaba salir de su vida presente, abandonar a su novia, dejar de vivir entre las sospechas de su madre y desaparecer sin explicaciones, como lo había hecho su padre. Al encontrar a su padre, se niega a abrazarle y confesar su reconocimiento; pero su plan de salir cambia en ese momento. Va a seguir la vida en la soledad, entre las sospechas de los suyos y entre los ataúdes.

La pieza no ofrece respuestas, y nos deja sólo adivinar en lo metafísico. Las relaciones de Alberto y su madre nos recuerdan las del niño Hipólito de La hiedra, que sospecha de su madrastra Teresa, y el interés fundamental del poeta en la muerte se revela no sólo en la inclinación morbosa que el protagonista muestra hacia la nada, 
sino también en la situación externa: el empleo de Alberto en la agencia de inhumaciones forma un marco apropiado a su melancólico deseo de soledad. Sin embargo, a pesar de ser un lugar raro para la acción de una obra literaria, tiene analogía en la literatura inglesa: si recordamos The loved one de Evelyn Waugh, notaremos un gran contraste entre ambas obras. El recinto que al novelista inglés le sirve para desarrollar una sátira preciosa y picante, estimula al poeta mexicano en su creación metafísica, llena de misteriosa nostalgia de causas desconocidas. Tanto como en sus poesías, en sus piezas Xavier Villaurrutia gusta del tono menor, del matiz sutil. Invitación a la muerte completa perfectamente la concepción del joven autor de los Nocturnos, de Nostalgia de la muerte, y de Décima muerte.

Bajo el interés por los problemas psicológicos, siempre notamos la corriente de la nostalgia de lo desconocido, casi al borde de una clarividencia del porvenir, que traería la muerte al poeta poco más tarde. A pesar de su influjo en todos los géneros literarios, ni el poeta ni el prosista podrán superar la excelencia del dramaturgo Xavier Villaurrutia. Su impacto en el teatro mexicano de vanguardia en el ségundo cuarto de nuestro siglo consiste en su participación como dramaturgo, director, traductor y actor. Por su colaboración en los teatros de la vanguardia el público mexicano conoció a autores como Jules Romains, H. R. Lenormand, Charles Vildrac, Jean Cocteau, Pirandello, Bontempelli, André Gide, Passeur, William Blake, O'Neill, Lord Dunsany y muchos otros. En sus artículos presentó Villaurrutia a sus lectores a Proust, a Pat1 Morand, y a numerosos artistas y pintores contemporáneos.

Entre los artistas que le gustaron más, hay que citar a André Gide, como escritor, y a Eric Satie, como compositor. Luigi Pirandello fué su dramaturgo predilecto, y prefería a Chirico a los demás pintores de fama mundial.

El interés dramático llevó también a Xavier Villaurrutia a escribir un argumento cinematográfico, en 1945. En La mulata de Córdoba se trata de dos familias de hacendados que viven en un pueblo de los alrededores de Córdoba, Veracruz, en 1910. Van a juntar las dos fortunas, por el matrimonio de Pedro Reyes y Emilia San Juan. La mulata del título, la Niña Sara, es hija y rica heredera de don Luis San Juan, tío de Emilia. La parentela no trata a 
Sara por su origen ilegítimo; pero el padre de Pedro es su amante clandestino. El día de la boda, Sara va a casa de los San Juan, y después de que casi la arrojan de alli, vuelve a su casa acompañada por el novio, Pedro, capturado en la red del encanto senstual de la mulata. Antes de acabar el drama, al padre de Emilia lo mata el criado de su sobrina Sara, quien se va desilusionado del amor de Pedro. Se vengó de la sociedad que no la había aceptado, pero se quedó sola, como Teresa, la viuda de La hiedra, y Sara, la mujer que a pesar de ser legítima, no acepta la hija del viudo Rafael en La mujer legítima. Alberto, en Invitación a la muerte también se quedó solo, y su padre, años antes, había salido solo, del hogar abandonando a su mujer. La soledad fundada en una fatalidad mística, persigue tanto a los protagonistas de las piezas como a los del argumento cinematográfico, y la voz de la sangre se oye en la trágica leyenda cordobesa como en el Yerro candente.

Por los vicios carnales, hay que pagar un precio de cariño $y$ de acato. María no reconoció a su padre, por haber abandonado tanto a ella como a su madre, mientras la Niña Sara, no reconocida por sus parientes, urde una venganza cruel. Conserva su fortuna, pero pierde el amor de Pedro, después de haber ordenado la muerte de su tío Carlos. ¡Más sangrienta no podría ser una trama cinematográfica!

El interés de Xavier Villaurrutia por el cinematógrafo, se revela, además, en un ensayo publicado en Cuadernos Americanos, en 1947. Dice en él: "La diferencia entre el diálogo cinematográfico y el teatral... es una diferencia de extensión." De los actores añade: "Las características y la función de los actores de teatro y cinematógrafo, son... las mismas, sólo que condicionadas en el cine por las distancias que la cámara reduce o agranda y por la falta de continuidad de la actuación del actor en el cinematógrafo."

Según Villaurrutia, "el tiempo cinematográfico nace... de que en los pies de película el fotógrafo ha capturado no la acción que transcurre en el tiempo y en el espacio reales ... sino partes escogidas, significativas de la acción en el espacio, y los no menos escogidos momentos de la acción en el tiempo, desde diferentes puntos de vista y en virtud de diferentes emplazamientos." Según él "el tiempo y el espacio cinematográficos se diferencian del tiempo y del espacio reales en que aquéllos están condicionados a la mayor o menor 
longitud de los pies de película impresionados y unidos el uno al otro ... Los pies de la película, al ser unidos, montados o editados . . . gracias a la previsión del autor o del director a la hora del rodaje y después de una selección a la hora del corte y en el momento de la edición, al sucederse... en la pantalla de una manera que ya no es real, dan, como resultado, una concentración del espacio y del tiempo ideales que escapan al tiempo real y que lo sustituyen."

Para Xavier Villaurrutia el drama es una forma superior de expresión literaria. Es "el resultado de una premeditada, lúcida, ponderada suma de substancias de otras artes... Las substancias que entran en su composición, desaparecen para dar lugar a una substancia nueva..."

Con rara sutileza poética, Xavier Villaurrutia siempre vuelve al arte dramático sin disminuir la calidad de su poesía. Al contrario, hasta su poesía está construída en función del tacto y de la vista. Hay en Villaurrutia una fusión consciente de lo poético y lo dramático, porque, según sus propias palabras, el poeta “dispone su obra de manera que sólo a través de la representación por medio de actores y frente al público real alcance su último propósito, se convierta en un poema dramático." 4

El año de 1947 vió el estreno, en el Palacio de Bellas Artes, de su comedia El pobre Barba Azul bajo la dirección del autor. Es un estudio dramático del alma humana, lleno de simpatía por los motivos y las debilidades que atormentan el espíritu. A1 protagonista, Samuel, despreciado por sus amigos y por las mujeres a causa. de su carácter débil, para darle más confianza, finge Carmen que lo ama, y en seguida se ponen todas las mujeres a correr tras él. Samuel estaba enamorado de Virginia, y en un momento de desesperación por el amor no correspondido, apareció Carmen y se dirigió a ella Samuel: “Tú, Carmen, me has enseñado a amar el amor, a amar, así, en abstracto. Yo soñaba ... Un día, aquel día en que se descubrió que todas las mujeres me querían, sólo porque tú habías puesto en mí los ojos, me despertaron ... de aquel sueño, ... me convencieron ... de que era un iluso enamorado del amor ... y comprendi... que yo no amaba en realidad sino a una sola persona, a la que me quería, a la que había descubierto que yo era digno de 
ser amado, Carmen, a ti!" Por supuesto, el amor de Carmen no era más que ficción, y al descubrir la verdad de que Carmen no lo ama, el pobre Barba Azul se queda otra vez abandonado por todos, lo que ya hemos notado acerca de otros protagonistas del dramaturgo de la nostalgia de la vida y de la muerte.

En el último año de su vida, 1950, Xavier Villaurrutia estrenó otra pieza, titulada: Juego peligroso, y publicó un monólogo: La tragedia de las equivocaciones. A pesar del tema nada original, Juego peligroso es una pieza convencional de buena factura.

En su obra dramática, Xavier Villaurrutia consiguió una colaboración entre el público y el actor, no obstante el juego de realidades contrarias entre la escena y la sala. La sutileza y la imaginación poética son la naturalidad de su teatro. No obstante la alta calidad de su poesía y su prosa, y de sus piezas más convencionales, estamos de acuerdo con las palabras que pronunció Celestino Gorostiza, en ocasión del primer aniversario de la muerte del dramaturgo refiriéndose a los "Autos profanos": "E1 verdadero Xavier Villaurrutia está en esas pequeñas obras maestras, verdaderos bocetos de las grandes obras que aún pudo haber escrito, de no haberle impuesto el silencio la muerte, cuando, después de apoderarse de la voluntad del público, y dueño ya de la seguridad y de la soltura que sólo los años y la experiencia proporcionan, hubiera vuelto a operar el magnífico instrumento que él mismo se forjó para jugar el gran juego del teatro." Acertadamente caracterizó a este poeta de la muerte y de su misterio, otro de sus amigos, Rodolfo Usigli, cuando escribió: "Xavier Villaurrutia es el poeta contemporáneo que define en México la crisis de la sensibilidad del mundo moderno, como los poetas metafísicos del principio del siglo xvir lo hacen en Inglaterra."

Esa senbilidad atrajo al poeta irresistiblemente a la muerte, hasta que la muerte se lo llevó. Nos despojó de él prematuramente, dejándonos en su obra su espíritu de nostalgia y de poética melancolia.

Vera F. Beck, New York. 


\section{$\mathrm{N} O \mathrm{O} A \mathrm{~S}$}

1 Romance, 1940, I, 4: Ocho contestaciones y preguntas.

2 Octavio Paz, El teatro de Xavier Villaurrutia, Sur, xIr, 105, 1943.

3 Letras de México, abril de 1944.

4 Cuadernos Americanos, vi, 3, 1947.

5 Estética de la muerte: El hijo pródigo, julio de 1946. 
